\title{
Treatment of Patients with Recently Exacerbated Schizophrenia with Paliperidone Palmitate: A Pilot Study of Efficacy and Tolerability
}

This article was published in the following Dove Press journal:

Neuropsychiatric Disease and Treatment

\author{
Wagner F Gattaz' \\ Ricardo Saracco-Alvarez $\mathbb{D}^{2}$ \\ Claudiane Salles Daltio ${ }^{3}$ \\ Martinus T Van de Bilt ${ }^{1}$ \\ Jose Julian Ortegón (1D ${ }^{4}$ \\ Sergio J Villaseñor-Bayardo (iD ${ }^{5}$ \\ Mario Louzã $\mathbb{D}^{6}$ \\ Helio Elkis $\mathbb{D}^{6}$ \\ Bernardo Soares $^{7}$ \\ Patricia Cabrera Jaramillo ${ }^{7}$ \\ Fabio Lawson ${ }^{7}$ \\ Leonardo Díaz-Galvis ${ }^{8}$
}

'Laboratory of Neuroscience (LIM27), Instituto de Psiquiatria do Hospital das Clinicas da Faculdade de Medicina, Universidade de São Paulo, São Paulo, Brazil; ${ }^{2}$ Instituto Nacional de Psiquiatría Ramón de la Fuentel, México D.F., México; ${ }^{3}$ Proesq - Unifesp

Schizophrenia Program - Federal University of São Paulo, São Paulo, Brazil; ${ }^{4}$ Centro de Investigaciones del Sistema Nervioso, Grupo Cisne, Bogotá, Colombia; ${ }^{5}$ University of Guadalajara, Mexico, Hospital Civil de Guadalajara, "Fray Antonio Alcalde", Guadalajara, Mexico; 'Instituto de Psiquiatria do HCFMUSP, São Paulo, Brazil; ${ }^{7}$ Medical Affairs, Janssen, Brazil; ${ }^{8}$ Medical Affairs, Janssen Canada, Toronto, ON, Canada
Background: Paliperidone palmitate is a long-acting, second-generation antipsychotic (SGA) indicated for the treatment of acute exacerbations and maintenance treatment of adults with schizophrenia. This study addressed the response to paliperidone palmitate in Latin American patients with acute symptoms and recently diagnosed schizophrenia.

Objective: Explore the efficacy and tolerability of paliperidone palmitate administered once a month for 4 months in patients with acute phase and recent diagnosis (within 1-6 years) of schizophrenia in 3 Latin American countries.

Methods: This was a non-randomized, open-label, multicenter study with paliperidone palmitate injected intramuscularly in the deltoid muscle at an initial loading dose of $150 \mathrm{mg}$ eq. (234 mg) on day 1 and $100 \mathrm{mg}$ eq. (156 mg) on day 8 ( \pm 4 days). The recommended maintenance dose was $75 \mathrm{mg}$ eq. $(117 \mathrm{mg})$ from day 36 to day 92. Efficacy was evaluated with PANSS and CGI-S. The last observation carried forward (LOCF) was used for efficacy analysis for imputation of missing data; no adjustments were made for multiplicity. Adverse events were evaluated during treatment.

Results: The patient retention rate was $84.0 \%$ (144 patients received study drug; 121 finished the study). The percentage of patients with a reduction of at least $30 \%$ in PANSS total score compared to baseline gradually increased during the study, and at the end, $78.4 \%$ of patients showed response. The PANSS total score and CGI-S scores decreased significantly from baseline to LOCF endpoint ( $P<0.0001$ for both); significant reduction in PANSS total score was observed at day 8 and persisted to the end of the study. Most common adverse events were muscle rigidity $(11.8 \%)$, akathisia $(11.1 \%)$, injection-site pain $(7.6 \%)$, weight gain (7.6\%), and insomnia (7.6\%).

Conclusion: Paliperidone palmitate was efficacious in Latin American patients studied with an acute exacerbation and recent diagnosis of schizophrenia, and no new safety signals were identified.

Keywords: paliperidone palmitate, recent onset, acute phase, schizophrenia

\section{Introduction}

Treatment adherence is one of the main problems in chronic diseases, given that approximately $60 \%$ of patients with chronic diseases show poor treatment adherence. ${ }^{1}$ Adherence plays a key role in achieving a better prognosis in the treatment of schizophrenia. ${ }^{2}$

Antipsychotics are the primary treatment for controlling acute psychotic episodes and preventing relapses in the long term. ${ }^{3,4}$ However, schizophrenia is accompanied by high relapse and rehospitalization rates, with poor adherence
Correspondence: Leonardo Díaz-Galvis Department of Medical Affairs, Janssen Inc, 19 Green Belt Dr, Toronto, ON

M3C IL9, Canada

Tel + I 4163825020

Email jldiaz0I@its.jnj.com 
being one of the main associated factors. ${ }^{5}$ Approximately $84 \%$ of patients with schizophrenia discontinue antipsychotic medication during treatment, ${ }^{6}$ and $40 \%$ to $50 \%$ of patients do not adequately comply with treatment in the long term. ${ }^{7}$ These percentages are similar between patients receiving first-generation antipsychotics (FGAs) and those receiving second-generation antipsychotics (SGAs). ${ }^{8}$

Eighty-two percent of patients diagnosed with a first episode of schizophrenia or schizoaffective disorder have at least one relapse during the first 5 years after initial recovery, and the risk of relapse is increased 5-fold in patients discontinuing treatment. ${ }^{9}$ On the other hand, over $35 \%$ of patients entering treatment have problems following the treatment protocol within the first 6 weeks, and non-adherence increases up to $75 \%$ after 2 years of treatment. ${ }^{10,11}$

Depot FGAs were introduced in the 1960s and were developed with the goal of improving adherence; however, their effect on negative symptoms was absent or modest, and their association with side effects, such as extrapyramidal symptoms and increased prolactin levels, limited their use over time. ${ }^{12}$ In recent years, long-acting injectable (LAI) SGAs have appeared as an alternative to increase adherence and improve prognosis, while decreasing side effects. ${ }^{13-15}$ In a systematic review of long-term studies, FGAs and SGAs were reported to reduce relapse rates in outpatients with schizophrenia from an average of $33.2 \%$ to $21.5 \%{ }^{16}$

Although the evidence indicates a decrease in relapse rates and better treatment compliance with LAI antipsychotics, their prescription is limited by a lack of knowledge about the use of these dosage forms and the preconceived notion that they are only suitable for a specific group of patients, usually chronic and severe patients and those with poor adherence. ${ }^{17,18}$ Additionally, LAI antipsychotics are generally not prescribed to patients with a first psychotic episode or recent-onset schizophrenia, although non-adherence is closely linked to relapse during these phases. ${ }^{19}$ Apparently, the low prescription rates of these therapeutic options are related to an alleged aversion of injectable medication in patients with a first episode and negative attitudes associated with the use of LAI antipsychotics. ${ }^{20-22}$ Nevertheless, published literature suggests that LAI SGAs represent a promising solution because they are associated with fewer adverse effects and present adequate efficacy for reducing symptoms and relapse rates. ${ }^{15,23}$ This has led to a gradual increase in the prescribing of these drugs, while their adoption is still slow in some regions, such as Latin America. ${ }^{24}$ The aim of this open-label study was to explore the efficacy and tolerability of paliperidone palmitate administered once a month for 4 months in patients with acute-phase schizophrenia in 3 Latin American countries.

\section{Patients and Methods}

\section{Study Population}

Patients were recruited from outpatient and inpatient services in Mexico, Colombia, and Brazil (Supplemental Table 1). The study included men and women who were not pregnant or lactating between 18 and 40 years of age (inclusive) with a diagnosis of schizophrenia for at least 1 year but less than 6 years (ie, recent-onset) according to the criteria of the Diagnostic and Statistical Manual of Mental Disorders, Fourth Edition (DSM-IV) ${ }^{25}$ confirmed by the Mini International Neuropsychiatric Interview (MINI) Spanish Version 5.0.0 $0^{26}$ or Brazilian validated version 5.0. ${ }^{27}$ Patients were also required to have an acute exacerbation of psychosis lasting less than 4 weeks but more than 4 days, with a Positive And Negative Syndrome Scale (PANSS) total score of 70 to 120 (inclusive), and a score of 4 (moderately ill) or more on the Clinical Global Impression-Severity (CGI-S) scale at screening. All patients or their legally acceptable representatives provided signed informed consent prior to the study. The main exclusion criteria were a diagnosis of substance dependence (except nicotine and caffeine) according to the DSM-IV within 6 months prior to entry, treatment with an LAI antipsychotic within 3 injection cycles prior to baseline, a change of more than $10 \%$ in PANSS total score between screening and baseline assessment after the oral tolerability test, history of treatment resistance, history of malignant neuroleptic syndrome, history or current symptoms of tardive dyskinesia, any unstable systemic disease, and plans to conceive a child while enrolled in the study or within 50 days after the last dose of the drug under study.

An Independent Ethics Committee or Institutional Review Board at each study site (Supplemental Table 1) approved the protocol, and the study was carried out in accordance with the ethical principles in the Declaration of Helsinki and was consistent with Good Clinical Practices and applicable local regulations. This study was registered at ClinicalTrials.gov: NCT01448720.

\section{Study Design}

This was a non-randomized, open-label, multicenter study of paliperidone palmitate administered in a flexible dose 
regimen in patients with an acute exacerbation of schizophrenia from 3 countries in Latin America. The study consisted of 2 phases: a screening phase of up to 4 days and a treatment phase of 4 months (injections were administered from day 1 to day 92 at monthly intervals followed by a visit at the end of the study on day 120) without an extension phase.

\section{Study Medication}

Paliperidone palmitate was administered intramuscularly and according to the regimen approved in the United States for the initiation and maintenance of treatment, with an initial loading dose of $150 \mathrm{mg}$ eq. (234 mg) on day 1 and $100 \mathrm{mg}$ eq. (156 mg) on day 8 ( \pm 4 days) in the deltoid muscle. The recommended maintenance dose was $75 \mathrm{mg}$ eq. $(117 \mathrm{mg}$ ) from day 36 to day 92 at monthly intervals in the deltoid or gluteal muscle at the discretion of the investigator, depending on tolerability. This maintenance dose could be increased or decreased at the discretion of the investigator based on efficacy in a range between $50 \mathrm{mg}$ eq. and $150 \mathrm{mg}$ eq. (flexible maintenance dose scheme).

Patients without prior exposure to risperidone or paliperidone were administered $1 \mathrm{mg}$ /day of oral risperidone or $3 \mathrm{mg} /$ day of extended-release (ER) OROS ${ }^{\circledR}$ paliperidone for at least 3 days in the screening phase, before the first injection of study drug for tolerability testing. Administration of other antipsychotics was allowed during the study at the discretion of the investigator, as was concomitant therapy with mood stabilizers, anticholinergics, benzodiazepines, hypnotics, or antidepressants.

\section{Assessments}

Efficacy was assessed at screening and on days 1, 4, 8, 36, 64, 92, and 120 (final assessment). Only qualified and trained raters (psychiatrists, psychiatry residents, or psychologists) who had $\geq 3$ years of experience evaluating patients with schizophrenia administered the PANSS. The primary efficacy endpoint was the proportion of patients with response to treatment, defined as the percentage of patients with a PANSS total score reduction of $\geq 30 \%$ at the final assessment compared to baseline. ${ }^{28}$ The 30 -item PANSS provided a total score (sum of the scores of all 30 items) and scores for 3 subscales: the positive syndrome subscale ( 7 items), the negative syndrome subscale (7 items), and the general psychopathology subscale (16 items). Each question was rated on a scale of 1 (absent) to 7 (extreme).
Secondary efficacy endpoints were changes from baseline at each time point in PANSS total score and PANSS Marder factor scores ${ }^{29}$ and CGI-S score. ${ }^{30}$ Additionally, the time to treatment failure was defined as the time to psychiatric hospitalization, presence of suicidal behavior, or discontinuation of the study drug due to lack of efficacy or safety or tolerability problems, at the discretion of the investigator.

Safety assessments performed during the study included adverse events, body weight/body mass index, assessment of extrapyramidal symptoms using the Abnormal Involuntary Movement Scale (AIMS), ${ }^{31}$ and presence of suicidal behavior using the InterSePT Scale for Suicidal Thinking-Plus (ISST-Plus). ${ }^{32}$ During screening and at the end of the study, lipid profile and fasting glucose were measured, and an electrocardiogram was performed.

\section{Statistical Analysis}

The size of the current sample was not based on any statistical power calculation because it was an exploratory study. A sample size of 150 patients entering the study was deemed to be sufficient to allow for a preliminary exploration of safety and efficacy in this open-label, single-arm study. Efficacy analyses were performed on the intent-totreat (ITT) population, which included all patients who received at least 1 dose of study drug. Categorical variables are presented as number and percentage of patients, and continuous variables are summarized using means and standard deviations (SDs). The last observation carried forward (LOCF) was used for the efficacy analysis for imputation of missing data. No adjustments of type I error for multiplicity were planned in order to account for multiplicity of primary variables.

Patients who showed a reduction in PANSS total score $\geq 30 \%$ were considered responders. The response was analyzed at each measurement point, including LOCF criteria. The time to first response (ie, reduction of $\geq 30 \%$ from baseline in PANSS total score), expressed as the number of days from the first injection until the first response, was analyzed using the Kaplan-Meier method.

Secondary efficacy was assessed using a paired $t$-test to establish differences in the change from baseline. The level of statistical significance was set at $P<0.05$, with 95\% confidence intervals (CIs).

Safety parameters were reported from observed data (without imputation) for the ITT population.

The data sharing policy of Janssen Pharmaceutical Companies of Johnson \& Johnson is available at https:// www.janssen.com/clinical-trials/transparency. As noted on 
this site, requests for access to the study data can be submitted through Yale Open Data Access (YODA) Project site at http://yoda.yale.edu.

\section{Results}

\section{Patient Disposition, Baseline Demographics, and Clinical Characteristics}

The initial study population was 151 patients, excluding 7 patients who did not receive the study drug. Thus, 144 patients were included in the ITT analysis. There was a predominance of men $(\mathrm{n}=101,70.1 \%)$, the mean age was 26.8 years $(\mathrm{SD}=6.2$; range, $18-41$ years), the mean age of onset of the first psychotic episode was 23.6 years ( $\mathrm{SD}=6.1$; range, 13-38.1 years), and the average time from DSM diagnosis to baseline was 2.9 years $(\mathrm{SD}=$ 1.3; range, 0.0-5.8 years). Twenty-five (17.4\%) patients reported having a psychiatric history, of which depression and drug abuse were most common, each occurring in 6 patients, and insomnia occurred in 3 patients. Previous hospitalization was reported for 75 (52.1\%) patients, but most patients (128/144 [88.9\%]) entered the study as outpatients, with a mean time since last hospitalization of 31.2 days ( $\mathrm{SD}=49.0$ days).

Enrolled patients had an acute psychotic episode reflected by a mean baseline PANSS total score of 95.1 $(\mathrm{SD}=14.7)$ and a mean CGI-S of $4.8(\mathrm{SD}=0.7)$. Mean time-to-readiness for discharge in the ITT hospitalized population was 40.0 days ( $\mathrm{SD}=23.0$; range, $13-73$ days).

The patient retention rate in the study was $84.0 \% ; 121$ patients finished the study. The most common reasons for discontinuation were withdrawal of consent (5.6\%), treatment failure $(3.5 \%)$, adverse event $(2.8 \%)$, and loss to follow-up $(2.1 \%)$.

\section{Treatment Exposure and Concomitant Treatment}

Tolerability testing was performed in 64 patients $(44.4 \%)$; of these, 47 patients received risperidone (73.4\%) and 17 received paliperidone ER (26.6\%). The patients received an average of 5 injections ( $\mathrm{SD}=1$; range, $2-5)$. The mean time from baseline to the last application of paliperidone palmitate was 86 days ( $\mathrm{SD}=23$; range, 10-107 days).

The mean maintenance dose of paliperidone palmitate (after excluding the higher doses given at day 1 and day 8) was $96.84 \mathrm{mg}$ at day 92 .
In the ITT population, $55(38.2 \%)$ patients had received previous psychotropic medications and 88 (61.1\%) patients were receiving concomitant psychotropic medications at baseline evaluation (Table 1). Mean doses of previous (at baseline) and current psychotropic medication decreased during the study, but the difference was not statistically significant. The most common antipsychotics that patients initiated during the study were oral

Table I Previous and Final Psychotropic Treatment, ITT Population $(\mathrm{N}=144)$

\begin{tabular}{|c|c|c|}
\hline Medication & $\begin{array}{l}\text { Previous } \\
\text { n (\%) }\end{array}$ & $\begin{array}{l}\text { End of Study } \\
n(\%)\end{array}$ \\
\hline \multicolumn{3}{|l|}{ Antipsychotics } \\
\hline Aripiprazole & $\mathrm{I}(0.7)$ & $\mathrm{I}(0.7)$ \\
\hline Chlorpromazine & $3(2.1)$ & $4(2.8)$ \\
\hline Clozapine & 0 & I (0.7) \\
\hline Haloperidol & $18(12.5)$ & $2(1.4)$ \\
\hline Levomepromazine & $3(2.1)$ & $7(4.9)$ \\
\hline Olanzapine & $13(9.0)$ & $13(9.0)$ \\
\hline Paliperidone & 0 & $4(2.8)$ \\
\hline Pipotiazine & $\mathrm{I}(0.7)$ & 0 \\
\hline Promethazine & $5(3.5)$ & $6(4.2)$ \\
\hline Quetiapine & $5(3.5)$ & $3(2.1)$ \\
\hline Risperidone & $30(20.8)$ & $30(20.8)$ \\
\hline Sertindole & $\mathrm{I}(0.7)$ & 0 \\
\hline Amisulpride & 0 & $\mathrm{I}(0.7)$ \\
\hline Sulpiride & $\mathrm{I}(0.7)$ & 0 \\
\hline Thioridazine & $\mathrm{I}(0.7)$ & 0 \\
\hline Trifluoperazine & $\mathrm{I}(0.7)$ & 0 \\
\hline Zuclopenthixol & I (0.7) & 0 \\
\hline \multicolumn{3}{|l|}{ Benzodiazepines } \\
\hline Alprazolam & 0 & $2(1.4)$ \\
\hline Clonazepam & $6(4.2)$ & $21(14.6)$ \\
\hline Diazepam & $4(2.8)$ & $6(4.2)$ \\
\hline Eszopiclone & 0 & $2(1.4)$ \\
\hline Lorazepam & $5(3.5)$ & $20(13.9)$ \\
\hline Midazolam & 0 & I (0.7) \\
\hline Nitrazepam & $\mathrm{I}(0.7)$ & 0 \\
\hline \multicolumn{3}{|l|}{ Anticholinergics } \\
\hline Biperiden & $9(6.3)$ & $31(21.5)$ \\
\hline \multicolumn{3}{|l|}{ Antidepressants } \\
\hline Fluoxetine & $2(1.4)$ & $4(2.8)$ \\
\hline Paroxetine & $\mathrm{I}(0.7)$ & $\mathrm{I}(0.7)$ \\
\hline Sertraline & I (0.7) & $5(3.5)$ \\
\hline \multicolumn{3}{|l|}{ Mood Stabilizers } \\
\hline Lithium & $3(2.1)$ & $3(2.1)$ \\
\hline Carbamazepine & 0 & $\mathrm{I}(0.7)$ \\
\hline Topiramate & $\mathrm{I}(0.7)$ & 0 \\
\hline Valproic acid & $3(2.1)$ & 0 \\
\hline
\end{tabular}


paliperidone and levomepromazine ( $\mathrm{n}=4$ each). Injectable and oral FGA treatments were reduced during the study. Benzodiazepines, anticholinergics, and antidepressants tended to be prescribed to a greater number of patients after starting the study. On the other hand, the prescription of mood stabilizers showed little change (Table 1).

\section{Efficacy}

The percentage of patients with a reduction of $\geq 30 \%$ in PANSS total score from baseline gradually increased during the study, with $59.6 \%$ of patients showing response after 36 days and $78.4 \%$ of patients showing response at LOCF endpoint visit (Figure 1). The mean time to response according to the criterion of a $\geq 30 \%$ reduction in PANSS total score from baseline was 48.5 days (SD = 2.93; $95 \%$ CI, 42.75 to 54.22 ), and the estimated median time to response was 35 days (interquartile range, 34-66 days).

Treatment failure according to our pre-established criteria occurred in $14(9.7 \%)$ patients an average of 54.0 days ( $\mathrm{SD}=38.0$; range, 2-123 days) after the first dose. Reasons for treatment failure were: $6(4.2 \%)$ substantial clinical deterioration, $5(3.5 \%)$ treatment discontinuations due to lack of efficacy, $4(2.8 \%)$ suicidal behavior, and
$3(2.1 \%)$ treatment discontinuations due to safety or tolerability concerns (patients may have 2 different reasons).

The PANSS total score decreased significantly during the study, with a mean change from baseline to endpoint [LOCF] of -32.7 (SD $=22.1 ; 95 \% \mathrm{CI},-36.4$ to -29.0 ; $P<0.0001$ ) (Figure 2). Statistically significant changes were also observed from baseline in CGI-S score at each visit and at LOCF endpoint $(P<0.0001)$. There was an early onset of antipsychotic effect, reducing symptoms in 8 days (PANSS total score change at day 8 from baseline $=-12.6$; $\mathrm{SD}=13.4 ; 95 \% \mathrm{CI},-14.8$ to $-10.4 ; P<0.0001)$.

\section{Safety}

Safety analysis was performed on the ITT population $(\mathrm{n}=$ 144). During the study, $63.9 \%$ of patients reported at least 1 adverse event. The most common adverse events were muscle rigidity $(11.8 \%)$, akathisia $(11.1 \%)$, pain associated with the injection $(7.6 \%)$, weight gain $(7.6 \%)$, and insomnia (7.6\%; Table 2). Two (1.4\%) serious adverse events were recorded, 1 psychotic episode and another patient with weight loss. Four (2.8\%) patients had 5 adverse events that resulted in treatment discontinuation: agitation, akathisia, hyperglycemia, psychotic disorder, and weight decrease. Mean body weight at baseline was $73.6 \mathrm{~kg}(\mathrm{SD}=$ $17.3)$; mean body weight at endpoint was $75.6 \mathrm{~kg}(\mathrm{SD}=$

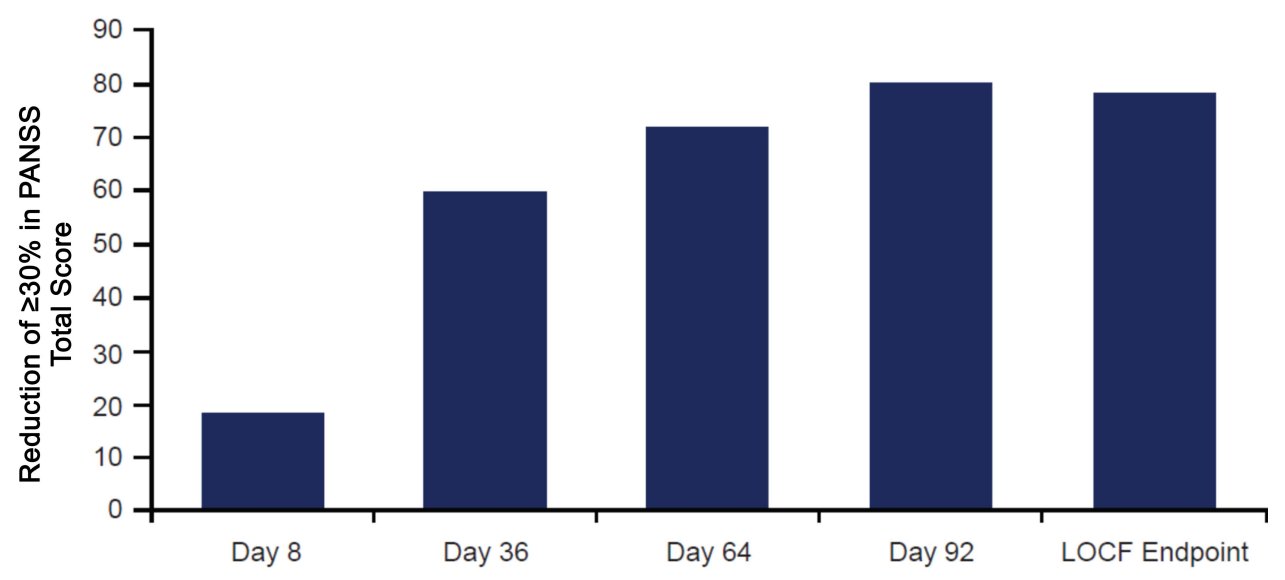

\begin{tabular}{|l|l|l|l|}
\hline Visit & $\mathrm{n}(\%)^{\mathrm{b}}$ & $95 \% \mathrm{Cl}$ & $P$-value \\
\hline Day 8 & $26(18.2)$ & 11.88 to 24.52 & 1.00 \\
\hline Day 36 & $81(59.6)$ & 51.35 to 67.85 & $<0.0001$ \\
\hline Day 64 & $92(71.9)$ & 64.11 to 79.69 & $<0.0001$ \\
\hline Day 92 & $98(80.3)$ & 73.24 to 87.36 & $<0.0001$ \\
\hline Endpoint & $109(78.4)$ & 71.56 to 85.24 & $<0.0001$ \\
\hline
\end{tabular}

Figure I Reduction of $\geq 30 \%$ in PANSS total score with respect to baseline visit: LOCF/ITT population: a $P$-value corresponds to the test of hypothesis of $P=0.35$ on each visit: ${ }^{b}$ Note that not all patients in the ITT population had efficacy data at each time point evaluated and thus the total " $n$ " at each visit is not always the total population of 144 patients. 


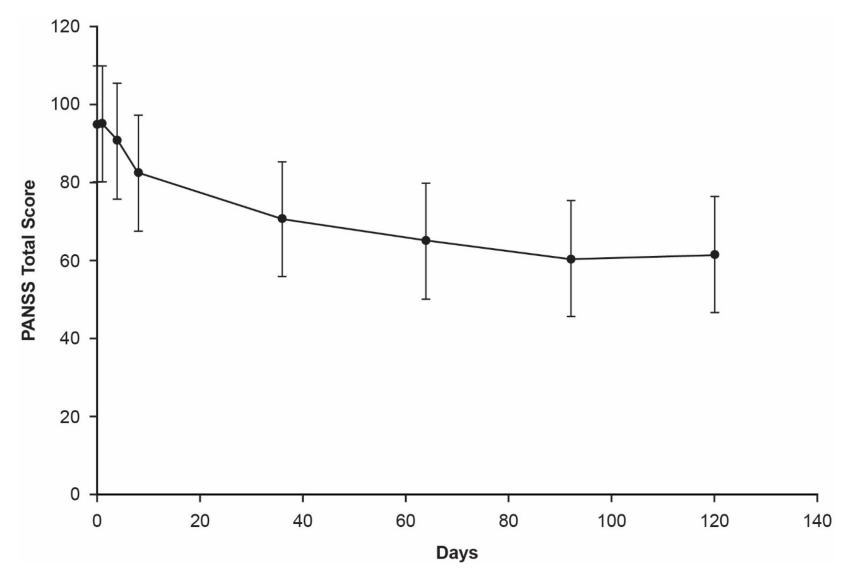

Figure 2 PANSS total scores over time in the ITT population. Mean $( \pm S D)$ based on raw score with $15 \%$ imputation rule applied on every point.

17.9). One adverse event was associated with increased prolactin $(0.7 \%)$.

The occurrence of extrapyramidal symptoms (eg, tardive dyskinesia) measured by the AIMS was low $(<4 \%)$ during the study, with a baseline mean (SD) of 0.4 (1.2) and an endpoint mean (SD) of 0.6 (2.1). No significant clinical changes were found at endpoint in relation to baseline in vital signs, laboratory parameters (including fasting glucose and lipid profile), or ECG recordings.

\section{Discussion}

In 3 Latin American countries, patients with recent-onset schizophrenia (diagnosis within 6 years of study

Table 2 Treatment-Emergent Adverse Events (ITT Analysis Set; $\mathrm{N}=$ 144)

\begin{tabular}{|l|l|}
\hline Most Common Adverse Events & n (\%) \\
\hline$\geq$ I TEAE & $92(63.9)$ \\
\hline EPS-related TEAEs & \\
Muscle rigidity & $17(1 \mathrm{I} .8)$ \\
Tremor & $8(5.6)$ \\
Parkinsonism & $2(1.4)$ \\
Dystonia & $4(2.8)$ \\
Dyskinesia & $2(1.4)$ \\
\hline Akathisia & $16(11.1)$ \\
Injection site pain & $11(7.6)$ \\
Weight increase & $11(7.6)$ \\
Insomnia & $11(7.6)$ \\
Somnolence & $9(6.3)$ \\
Anxiety & $8(5.6)$ \\
Headache & $7(4.9)$ \\
\hline
\end{tabular}

Abbreviations: TEAE, treatment-emergent adverse event; EPS, extrapyramidal symptom. screening) starting paliperidone palmitate intramuscularly (following prescription recommendations) during an acute episode of psychosis and subsequently treated with a monthly dose of $75 \mathrm{mg}$ eq. (117 mg) had improved clinical symptoms and overall disease status. A high proportion of patients responded to treatment with adequate tolerability.

These results are similar to randomized, placebocontrolled studies of paliperidone palmitate performed in patients with acute schizophrenia in other regions. ${ }^{33,34}$ A recent subgroup analysis of 2 large phase 3 trials supported the efficacy and safety of paliperidone palmitate every 3 months in Latin American patients, ${ }^{35}$ showing that more than $90 \%$ of patients remained relapse-free over 48 weeks. Patients with acute symptoms of schizophrenia and unsuccessful treatment with oral antipsychotics received paliperidone palmitate in an open-label, 6-month study in 21 countries across Europe and the United Kingdom. ${ }^{36}$ Twothirds of patients achieved $\geq 30 \%$ reduction in mean PANSS total score, with significant reductions observed as early as day 8 . A recent systematic review of monthly paliperidone palmitate in real-world evidence studies concluded that the treatment provides consistent results of reducing relapserelated events, including hospitalizations. ${ }^{37}$

The dosing regimen for paliperidone palmitate used in this study, with an initial loading dose of $150 \mathrm{mg}$ eq. (234 mg) on day 1 and $100 \mathrm{mg}$ eq. (156 mg) on day 8 in the deltoid muscle, followed by a monthly maintenance dose of $75 \mathrm{mg}$ eq. (117 $\mathrm{mg}$ ), produced a fast reduction in PANSS total score that was statistically significant at day 8 and persisted to the end of the study. This finding supports the early onset of antipsychotic effect after the first injection of paliperidone palmitate $150 \mathrm{mg}$ eq. and is consistent with what has been reported in previous studies. ${ }^{38-40}$ However, it is important to remember that the study allowed for the prescription of other antipsychotics, and their effect cannot be ruled out as potentiators of the response.

Between $2.3 \%$ and $9.3 \%$ of patients with newly diagnosed schizophrenia treated with paliperidone palmitate have extrapyramidal symptoms. ${ }^{41,42}$ Akathisia has been reported with a frequency of $1.9 \%$ in previous studies, being higher in patients with chronic schizophrenia. ${ }^{42}$ Compared with these previous reports, the frequencies of extrapyramidal symptoms (12.5\%) and akathisia (11.1\%) were higher in this study and were most likely related to the maintenance of other antipsychotic therapies and to the fact that oral paliperidone was added for some patients. 
During the study, FGA oral and injectable antipsychotics were discontinued or reduced, while oral SGAs risperidone, olanzapine, and aripiprazole were unchanged. The use of other antipsychotics varied but only in a small proportion of the study population. This pattern of prescribing oral antipsychotics in conjunction with the proposed regimen for paliperidone palmitate could also be related to the increase in the use of concomitant therapy, mainly with biperiden and benzodiazepines for the management of extrapyramidal symptoms and akathisia. Additionally, because patients received paliperidone palmitate until the last observation and there was no extension phase, it is unknown whether tardive dyskinesia occurred after discontinuation of the study drug. Other adverse events reported were pain at the injection site, weight gain, insomnia, drowsiness, headache, and anxiety. Adverse events were similar to those observed in other studies with paliperidone palmitate. ${ }^{42,43}$

It has been suggested that LAI antipsychotics may be a particularly suitable treatment option for patients with early schizophrenia. The first 5 to 10 years of the disease are critical to establish an adequate control of symptoms to help prevent clinical deterioration and reduce the risk of relapse due to non-adherence. ${ }^{44,45}$ Patients with recent schizophrenia are likely to have treatment adherence problems due to lack of insight regarding their illness and their need for treatment. They are also likely to lack social support and to abandon treatment by their own choice. ${ }^{46}$ On the other hand, in the early stages of schizophrenia, a better response to antipsychotic treatment ${ }^{47}$ and increased susceptibility to adverse events ${ }^{48}$ are observed. The presence of adverse events is another factor associated with treatment discontinuation in patients with recent schizophrenia. The recommendation to start with an initial loading dose of $150 \mathrm{mg}$ eq. of paliperidone palmitate, followed by a dose of $100 \mathrm{mg}$ eq. on day 8 in the deltoid muscle, and a monthly maintenance dose of $75 \mathrm{mg}$ eq., could raise concerns of causing more side effects in patients with early-stage schizophrenia. The International Clinical Guidelines for Early Psychosis and the World Psychiatric Association recommend the minimum effective dose whenever possible. ${ }^{49}$

Our use of a loading dose of paliperidone palmitate was based on reports of its efficacy and tolerability. ${ }^{34,50}$ Lower initial doses administered in the gluteal muscle may lead to subtherapeutic plasma levels and poor long-term response in schizophrenia. ${ }^{51}$ This study reported an excellent retention rate $(84 \%)$, a good response, and a suitable tolerability profile. However, it is not possible to rule out the effect of oral antipsychotics prescribed during the study on treatment efficacy and the increase of some adverse events.

Data interpretation in this study is limited by the use of an open-label design, the short duration, the limited number of patients, and the lack of a comparison group. As this was an exploratory study, the intention was not to compare treatment with paliperidone palmitate to another treatment (eg, comparator or placebo). Additionally, the fact that oral antipsychotics were maintained and concomitant therapy with anticholinergics, benzodiazepines, mood stabilizers, and antidepressants was allowed during the study could lead to bias in the interpretation of the efficacy and safety results. Moreover, 5 patients started on new oral antipsychotics during the treatment phase, and doses of current antipsychotics could be changed during the study. While this open-label design and use of concomitant medications reflect current real-world clinical practice for the management of patients with recent schizophrenia during an acute episode, it is a very significant limitation of the study. Together, these factors limit the strength of the conclusions and the generalization of the efficacy and safety of paliperidone palmitate in patients with an acute episode of schizophrenia in a Latin American population (Mexico, Colombia, and Brazil).

It is worth highlighting the pattern observed for the prescription of oral antipsychotics during the study, as it could reflect a lack of confidence in the clinical efficacy of LAI SGAs in the early phases of the disease and in acute episodes of psychosis. One of the main barriers to the initiation of treatment with LAIs is that psychiatrists often assume that patients with a first episode of psychosis or early schizophrenia would reject injectable antipsychotics. Psychiatrists believe it would be difficult to convince patients of the need, as they have not yet experienced relapses. Patients may also regard the treatment as a coercive measure, so psychiatrists often reserve this therapy for chronic patients. ${ }^{52}$ There is a high relapse rate in the early phases of schizophrenia, and LAI SGAs are a valid therapeutic option considered in the clinical guidelines. ${ }^{53}$ However, their use is limited due to several reasons, including physician reluctance to change prescribing habits, lack of physician knowledge on how to use these forms of drugs, and the misconception that LAI SGAs should only be used in a very specific group of people (ie, severely ill patients and those who have shown poor adherence). ${ }^{17,18,20-22,54}$ 


\section{Conclusions}

Results of this study demonstrated that paliperidone palmitate has an early onset of action in patients with an acute episode of schizophrenia. Paliperidone palmitate was efficacious at the recommended doses and no new safety signals were identified. Finally, we suggest performing studies on the perception of psychiatrists regarding treatment with LAI SGAs in recently diagnosed patients and reviewing existing management guidelines in Latin America (Mexico, Colombia, and Brazil) due to the observed pattern of prescription of oral antipsychotics with paliperidone palmitate.

\section{Acknowledgments}

We thank the study participants, without whom this study would not have been accomplished, and all the investigators for their participation. We also thank Areté proyectos (Rogelio Apiquián) for writing assistance and Lisa Shannon, PharmD (MedErgy) for editorial assistance.

\section{Author Contributions}

All authors made substantial contributions to conception and design, acquisition of data, or analysis and interpretation of data; took part in drafting the article or revising it critically for important intellectual content; gave final approval of the version to be published; and agree to be accountable for all aspects of the work.

\section{Disclosure}

This research and editorial assistance for this manuscript were funded by Janssen Pharmaceutical, Latin America. Dr Bernardo Soares, Dr Patricia Cabrera Jaramillo, Dr Fabio Lawson, and Dr Leonardo Díaz-Galvis are employees of Janssen Pharmaceutical. All authors met the International Committee of Medical Journal Editors (ICMJE) criteria, and all those who fulfilled those criteria are listed as authors. All authors had access to the study data and made the final decision about where to publish these data and approved the submission to this journal.

Dr Martinus T Van de Bilt reports grants and non-financial support from Janssen Pharmaceuticals during the conduct of the study; and personal fees and non-financial support from Janssen Pharmaceuticals outside the submitted work. Dr Jose Julian Ortegón reports grants and non-financial support from Janssen during the conduct of the study. Dr Mario Louzã reports personal fees from Janssen, Cristália, and Hypera during the conduct of the study. Prof Dr Helio Elkis reports grants from Fapesp, and other support from Aché, Cristália, Daiichi-Sankyo, Janssen, and Mantecorp-Hypera during the conduct of the study. Dr Bernardo Soares reports other support from Janssen Cilag during the conduct of the study. Dr Patricia Cabrera Jaramillo reports other support from MedErgy during the conduct of the study. Dr Fabio Lawson reports grants, personal fees, and other support from Janssen during the conduct of the study; and grants, personal fees, and other support from Janssen outside the submitted work. Dr Leonardo Díaz-Galvis reports other support from Janssen during the conduct of the study; and other support from Janssen outside the submitted work. The authors report no other conflicts of interest in this work.

\section{References}

1. Dunbar-Jacob J, Mortimer-Stephens MK. Treatment adherence in chronic disease. $J$ Clin Epidemiol. 2001;54(Suppl 1):S57-S60. doi:10.1016/S0895-4356(01)00457-7

2. Masand PS, Roca M, Turner MS, Kane JM. Partial adherence to antipsychotic medication impacts the course of illness in patients with schizophrenia: a review. Prim Care Companion J Clin Psychiatry. 2009;11(4):147-154. doi:10.4088/PCC.08r00612

3. Lehman AF, Steinwachs DM. Translating research into practice: the Schizophrenia Patient Outcomes Research Team (PORT) treatment recommendations. Schizophr Bull. 1998;24(1):1-10. doi:10.1093/ oxfordjournals.schbul.a033302

4. Lehman AF, Kreyenbuhl J, Buchanan RW, et al. The Schizophrenia Patient Outcomes Research Team (PORT): updated treatment recommendations 2003. Schizophr Bull. 2004;30(2):193-217. doi:10.1093/ oxfordjournals.schbul.a007071

5. Velligan DI, Weiden PJ, Sajatovic M, et al. Strategies for addressing adherence problems in patients with serious and persistent mental illness: recommendations from the expert consensus guidelines. J Psychiatr Pract. 2010;16(5):306-324. doi:10.1097/01.pra.00003 88626.98662.a0

6. Kreyenbuhl J, Slade EP, Medoff DR, et al. Time to discontinuation of first- and second-generation antipsychotic medications in the treatment of schizophrenia. Schizophr Res. 2011;131(13):127-132. doi:10.1016/j.schres.2011.04.028

7. Lacro JP, Dunn LB, Dolder CR, Leckband SG, Jeste DV. Prevalence of and risk factors for medication nonadherence in patients with schizophrenia: a comprehensive review of recent literature. J Clin Psychiatry. 2002;63(10):892-909. doi:10.4088/JCP.v63n1007

8. Velligan DI, Weiden PJ, Sajatovic M, et al. The expert consensus guideline series: adherence problems in patients with serious and persistent mental illness. J Clin Psychiatry. 2009;70(Suppl 4):1-46; quiz 47-48. doi:10.4088/JCP.7090su1cj

9. Robinson D, Woerner MG, Alvir JM, et al. Predictors of relapse following response from a first episode of schizophrenia or schizoaffective disorder. Arch Gen Psychiatry. 1999;56(3):241-247. doi:10. 1001/archpsyc.56.3.241

10. Weiden P, Rapkin B, Zygmunt A, Mott T, Goldman D, Frances A. Postdischarge medication compliance of inpatients converted from an oral to a depot neuroleptic regimen. Psychiatr Serv. 1995;46 (10):1049-1054.

11. Weiden PJ. Discontinuing and switching antipsychotic medications: understanding the CATIE schizophrenia trial. J Clin Psychiatry. 2007;68(Suppl 1):12-19. 
12. Bishara D. Once-monthly paliperidone injection for the treatment of schizophrenia. Neuropsychiatr Dis Treat. 2010;6:561-572. doi:10. 2147/NDT.S8505

13. Nasrallah HA, Lasser R. Improving patient outcomes in schizophrenia: achieving remission. J Psychopharmacol. 2006;20(6 Suppl): 57-61. doi:10.1177/1359786806071248

14. Kaplan G, Casoy J, Zummo J. Impact of long-acting injectable antipsychotics on medication adherence and clinical, functional, and economic outcomes of schizophrenia. Patient Prefer Adherence. 2013;7:1171-1180. doi:10.2147/PPA.S53795

15. Marcus SC, Zummo J, Pettit AR, Stoddard J, Doshi JA. Antipsychotic adherence and rehospitalization in schizophrenia patients receiving oral versus long-acting injectable antipsychotics following hospital discharge. J Manag Care Spec Pharm. 2015;21 (9):754-768. doi:10.18553/jmcp.2015.21.9.754

16. Leucht C, Heres S, Kane JM, Kissling W, Davis JM, Leucht S. Oral versus depot antipsychotic drugs for schizophrenia-a critical systematic review and meta-analysis of randomised long-term trials. Schizophr Res. 2011;127(13):83-92. doi:10.1016/j.schres.2010.11.020

17. Velligan DI, Medellin E, Draper M, et al. Barriers to, and strategies for, starting a long acting injection clinic in a community mental health center. Community Ment Health J. 2011;47(6):654-659. doi:10.1007/s10597-011-9389-6

18. Parellada E, Bioque M. Barriers to the use of long-acting injectable antipsychotics in the management of schizophrenia. CNS Drugs. 2016;30(8):689-701. doi:10.1007/s40263-016-0350-7

19. Emsley R, Oosthuizen P, Koen L, Niehaus DJ, Medori R, Rabinowitz J. Remission in patients with first-episode schizophrenia receiving assured antipsychotic medication: a study with risperidone long-acting injection. Int Clin Psychopharmacol. 2008;23 (6):325-331. doi:10.1097/YIC.0b013e32830c2042

20. Patel MX, Haddad PM, Chaudhry IB, McLoughlin S, Husain N, David AS. Psychiatrists' use, knowledge and attitudes to firstand second-generation antipsychotic long-acting injections: comparisons over 5 years. $J$ Psychopharmacol. 2010;24(10):1473-1482. doi:10.1177/0269881109104882

21. Waddell L, Taylor M. Attitudes of patients and mental health staff to antipsychotic long-acting injections: systematic review. $\mathrm{Br}$ J Psychiatry Suppl. 2009;52:S43-S50. doi:10.1192/bjp.195.52.s43

22. Correll CU, Citrome L, Haddad PM, et al. The use of long-acting injectable antipsychotics in schizophrenia: evaluating the evidence. J Clin Psychiatry. 2016;77(suppl 3):1-24. doi:10.4088/JCP.15032su1

23. Lafeuille MH, Dean J, Carter V, et al. Systematic review of long-acting injectables versus oral atypical antipsychotics on hospitalization in schizophrenia. Curr Med Res Opin. 2014;30 (8):1643-1655. doi:10.1185/03007995.2014.915211

24. Maia-de-Oliveira JP, Bressan RA, Elkis H, Machado-de-Sousa JP, Hallak JE. Why we should use long-acting injectable antipsychotics more frequently. Braz $J$ Psychiatry. 2013;35(3):217-218. doi:10.1590/1516-4446-2013-3503

25. American Psychiatric Association. Diagnostic and Statistical Manual of Mental Disorders: DSM-IV. Washington, DC: American Psychiatric Association; 1994.

26. Heinze G, Sheehan D. Mini International Neuropsychiatric Interview. Versión En Español 5.0.0 DSM-IV. Mini International Neuropsychiatric Interview (MINI): Spanish Version (South and Central America) 5.0.0.DSM-IV. México, DF: Instituto Nacional de Psiquiatría; 2000.

27. Amorim P. Mini International Neuropsychiatric Interview (MINI): validation of a short structured diagnostic psychiatric interview. Braz $J$ Psychiatry. 2000;22:106-115. doi:10.1590/S1516-44462000000300003

28. Kay SR, Fiszbein A, Opler LA. The Positive And Negative Syndrome Scale (PANSS) for schizophrenia. Schizophr Bull. 1987;13(2):261-276. doi:10.1093/schbul/13.2.261
29. Marder SR, Davis JM, Chouinard G. The effects of risperidone on the five dimensions of schizophrenia derived by factor analysis: combined results of the North American trials. J Clin Psychiatry. 1997;58 (12):538-546. doi:10.4088/JCP.v58n1205

30. Guy W. ECDEU Assessment Manual for Psychopharmacology Revised, 1976. (Clinical Global Impressions [CGI]); 1976:218-222.

31. Guy W. ECDEU Assessment Manual for Psychopharmacology Revised, 1976. Abnormal Involuntary Movement Scale (AIMS); 1976.

32. Lindenmayer JP, Czobor P, Alphs L, et al. The InterSePT scale for suicidal thinking reliability and validity. Schizophr Res. 2003;63(12):161-170. doi:10.1016/S0920-9964(02)00335-3

33. Gopal S, Hough DW, Xu H, et al. Efficacy and safety of paliperidone palmitate in adult patients with acutely symptomatic schizophrenia: a randomized, double-blind, placebo-controlled, dose-response study. Int Clin Psychopharmacol. 2010;25(5):247-256. doi:10.1097/YIC.0b 013e32833948fa

34. Pandina GJ, Lindenmayer JP, Lull J, et al. A randomized, placebo-controlled study to assess the efficacy and safety of 3 doses of paliperidone palmitate in adults with acutely exacerbated schizophrenia. J Clin Psychopharmacol. 2010;30(3):235-244. doi:10.1097/JCP.0b013e3181dd3103

35. Savitz AJ, Xu H, Gopal S, Nuamah I, Mathews M, Soares B. Efficacy and safety of paliperidone palmitate 3-month formulation in Latin American patients with schizophrenia: a subgroup analysis of data from two large phase 3 randomized, double-blind studies. Braz J Psychiatry. 2019;41(6):499-510. doi:10.1590/1516-4446-2018-0153

36. Hargarter L, Cherubin P, Bergmans $\mathrm{P}$, et al. Intramuscular long-acting paliperidone palmitate in acute patients with schizophrenia unsuccessfully treated with oral antipsychotics. Prog Neuropsychopharmacol Biol Psychiatry. 2015;58:1-7. doi:10.1016/j.pnpbp.2014.11.006

37. Emsley R, Parellada E, Bioque M, Herrera B, Hernando T, GarciaDorado M. Real-world data on paliperidone palmitate for the treatment of schizophrenia and other psychotic disorders: a systematic review of randomized and nonrandomized studies. Int Clin Psychopharmacol. 2018;33(1):15-33. doi:10.1097/YIC.0000000000 000195

38. Alphs L, Bossie CA, Sliwa JK, Ma YW, Turner N. Onset of efficacy with acute long-acting injectable paliperidone palmitate treatment in markedly to severely ill patients with schizophrenia: post hoc analysis of a randomized, double-blind clinical trial. Ann Gen Psychiatry. 2011;10(1):12. doi:10.1186/1744-859X-10-12

39. Agid O, Kapur S, Arenovich T, Zipursky RB. Delayed-onset hypothesis of antipsychotic action: a hypothesis tested and rejected. Arch Gen Psychiatry. 2003;60(12):1228-1235. doi:10.1001/archpsyc.60. 12.1228

40. Leucht S, Busch R, Hamann J, Kissling W, Kane JM. Early-onset hypothesis of antipsychotic drug action: a hypothesis tested, confirmed and extended. Biol Psychiatry. 2005;57(12):1543-1549. doi:10.1016/j.biopsych.2005.02.023

41. Gopal S, Liu Y, Alphs L, Savitz A, Nuamah I, Hough D. Incidence and time course of extrapyramidal symptoms with oral and long-acting injectable paliperidone: a posthoc pooled analysis of seven randomized controlled studies. Neuropsychiatr Dis Treat. 2013;9:1381-1392. doi:10.2147/NDT.S49944

42. Sliwa JK, Bossie CA, Fu DJ, Turkoz I, Alphs L. Long-term tolerability of once-monthly injectable paliperidone palmitate in subjects with recently diagnosed schizophrenia. Neuropsychiatr Dis Treat. 2012;8:375-385. doi:10.2147/NDT.S32581

43. Kramer M, Litman R, Hough D, et al. Paliperidone palmitate, a potential long-acting treatment for patients with schizophrenia. Results of a randomized, double-blind, placebo-controlled efficacy and safety study. Int J Neuropsychopharmacol. 2010;13(5):635-647. doi:10.1017/S1461145709990988 
44. Weiden PJ, Schooler NR, Weedon JC, Elmouchtari A, Sunakawa A, Goldfinger SM. A randomized controlled trial of long-acting injectable risperidone vs continuation on oral atypical antipsychotics for first-episode schizophrenia patients: initial adherence outcome. J Clin Psychiatry. 2009;70(10):1397-1406.

45. Keshavan MS, Amirsadri A. Early intervention in schizophrenia: current and future perspectives. Curr Psychiatry Rep. 2007;9 (4):325-328. doi:10.1007/s11920-007-0040-8

46. Tiihonen J, Haukka J, Taylor M, Haddad PM, Patel MX, Korhonen P. A nationwide cohort study of oral and depot antipsychotics after first hospitalization for schizophrenia. Am J Psychiatry. 2011;168 (6):603-609. doi:10.1176/appi.ajp.2011.10081224

47. Perkins DO, Gu H, Boteva K, Lieberman JA. Relationship between duration of untreated psychosis and outcome in first-episode schizophrenia: a critical review and meta-analysis. Am J Psychiatry. 2005;162(10):1785-1804. doi:10.1176/appi.ajp.162.10.1785

48. Lieberman JA, Perkins D, Belger A, et al. The early stages of schizophrenia: speculations on pathogenesis, pathophysiology, and therapeutic approaches. Biol Psychiatry. 2001;50(11):884-897. doi:10.1016/S0006-3223(01)01303-8

49. International Early Psychosis Association Writing Group. International clinical practice guidelines for early psychosis. $\mathrm{Br}$ J Psychiatry Suppl. 2005;48:S120-S124. doi:10.1192/bjp.187.48. s120
50. Bossie CA, Fu DJ, Sliwa JK, Ma YW, Alphs L. Tolerability of initiation doses of once-monthly paliperidone palmitate in patients with recently diagnosed schizophrenia in an acute treatment trial. Ther $A d v$ Psychopharmacol. 2011;1(4):111-124. doi:10.1177/2045125311413006

51. Gopal S, Gassmann-Mayer C, Palumbo J, Samtani MN, Shiwach R, Alphs L. Practical guidance for dosing and switching paliperidone palmitate treatment in patients with schizophrenia. Curr Med Res Opin. 2010;26(2):377-387. doi:10.1185/03007990903482772

52. Kirschner M, Theodoridou A, Fusar-Poli P, Kaiser S, Jager M. Patients' and clinicians' attitude towards long-acting depot antipsychotics in subjects with a first episode of psychosis. Ther Adv Psychopharmacol. 2013;3(2):89-99. doi:10.1177/2045125312464106

53. Verduzco W. Guía basada en la evidencia de la asociación psiquiátrica de américa latina y de la asociación psiquiátrica mexicana para el tratamiento del paciente con esquizo frenia. Salud Mental. 2014;37:96.

54. Apiquian R, Cordoba R, Louza M. Clinical outcomes of long-acting injectable risperidone in patients with schizophrenia: six-month follow-up from the Electronic Schizophrenia Treatment Adherence Registry in Latin America. Neuropsychiatr Dis Treat. 2010;7:19-26. doi:10.2147/NDT.S15911

\section{Publish your work in this journal}

Neuropsychiatric Disease and Treatment is an international, peerreviewed journal of clinical therapeutics and pharmacology focusing on concise rapid reporting of clinical or pre-clinical studies on a range of neuropsychiatric and neurological disorders. This journal is indexed on PubMed Central, the 'PsycINFO' database and CAS, and is the official journal of The International Neuropsychiatric Association (INA). The manuscript management system is completely online and includes a very quick and fair peer-review system, which is all easy to use. Visit http://www.dovepress.com/testimonials.php to read real quotes from published authors. 